\title{
Interpretation of Whorf from Different Perspectives
}

\author{
Yanlong Wang \\ Hohhot, Inner Mongolia, China \\ E-mail: wangyanlongneida@sina.com
}

Doi:10.7575/aiac.alls.v.7n.1p.226

URL: http://dx.doi.org/10.7575/aiac.alls.v.7n.1p.226
Received: 09/10/2015

Accepted: 20/12/2015

\begin{abstract}
The paper interprets Whorf's notion by turning to his original writings. Specifically, the paper makes a detailed analysis of Whorf's notion from anthropological linguistics, which largely deals with his famous distinction between overt category and covert category and his detailed description of the American Indian language Hopi; contrastive linguistics, which implies Whorf's research pedagogy by which the major differences between Hopi and English were found; and psycholinguistics which shows that Whorf would like to explore the deeper internalized meaning of language so as to uncover the true nature of language in the process of thinking. Therefore, the writer aims to have access to Whorf by rereading his original works and demonstrates what he has actually done in relation with those disciplines mentioned above.
\end{abstract}

Keywords: Whorf, anthropological linguistics, contrastive linguistics, psycholinguistics

\section{Introduction}

As has been known to all, Whorf's most understanding devotion to linguistics is his linguistic relativity. The paper, however, touches upon Whorf's other contributions. Specifically, Whorf actually explored the relationship between language and thought in such interdisciplinary fields as anthropological linguistics, contrastive linguistics and psycholinguistics. In this paper, some of Whorf's writings will be examined with great care to assist readers to have a better understanding towards Whorf's notion. Firstly, Whorf set about beginning his study of American Indian languages after he met Sapir, his tutor, in 1931. During his academic life, he made such a distinction between overt and covert category and had intensive examination of Hopi language and Mayan language, which actually put linguistic study at a higher level. Secondly, Whorf's comparison of SAE (Standard Average European) with Hopi makes explicit his innovative research methodology. Traditionally, researchers focused their attention on the comparison among SAE and had no intention of including some other minority languages in their research scope. Whorf's work is not simply aimed at making linguistic contrast of SAE and Hopi, but explores the implied meaning of those grammatical categories of the languages, which further shows that the different use of grammatical categories may lead to the different world views of the nation. Thirdly, Whorf's ideas shown in psycholinguistics will be presented in the last part of the paper in which Whorf's statements about psycholinguistic patterning are explored.

\section{Whorf and anthropological linguistics}

As is known to all that Whorf together with another two outstanding anthropological linguists Boas and Sapir has made great contributions to the development of American anthropological linguistics, and they are all the time regarded as "the great triumvirate of the Boasian tradition" (Foley, 2001, p.199). What they concern is not limited to the universally known languages such as English, German or French, but to the minority languages which are used by a few speakers. Whorf is the name closely related with the principle of linguistic relativity though much of his work was greatly affected by his tutor Sapir. Sapir $(1964$, p.128) maintained each language is a formally complete system, the diversity of which makes languages incommensurate with each other to some extent. Although Whorf followed some of his teacher's practices, yet trained as a natural scientist and taking great interest in the study of languages, he finally developed his research in his own way. He intended to make a contrast between English and Hopi language, aiming to uncover the discrepancy between the two different languages. He went further beyond the lexical comparison, thereby putting forward some famous definitions which are of great significance to the linguistic research. Whorf's interest in Mayan languages also helps open up his eyes and broaden his horizon in linguistic research.

\subsection{Phenotypes versus Cryptotypes}

Whorf's clear statement of covert categories or cryptotypes is found in his paper "Grammatical Categories" (Carroll, 1956), which was written during December 1937. In spite of the fact that the publication of the paper was postponed to 1946, the paper was known to his colleagues during his lifetime and gained their respects. By reading Whorf's original essay, we find that his goal in writing it was that it is desirable to avoid " [ $\mathrm{t}$ ] he very natural tendency to use terms derived from traditional grammar, like verb, noun, adjective, passive voice, in describing languages outside of IndoEuropean", mainly because Whorf believed that this practice "is fraught with grave possibilities of misunderstanding"(Carroll, 1956, p. 87). The concepts of covert categories and cryptotypes were thus introduced as part of a larger framework for grammatical analysis. In his paper, he made such a conclusiton that "Conventional 
grammar of American languages" are "based on classical models", which leads linguists to "restrict attention to the morphemes by which many grammatical forms are marked". He thus acclaimed that linguists should look for wordclasses which are not marked morphemically but rather "by types of patterning: e.g. by the systematic avoidance of certain morphemes, by lexical selection, by word-order that is also CLASS-ORDER, in general by association with definite linguistic configurations" (Carroll, 1956, pp. 87-88).

Whorf, in the anthology compiled by Carroll (1956, p. 55) shared with Boas and Sapir the view that language can organize experience. But he went beyond Boas and Sapir to distinguish two types of classification and all Whorf's analytical framework was built around these two fundamental distinctions, the one between overt and covert categories and the other between 'selective' and 'modulus' categories (ibid, p. 93). Next, the detailed analyses will be made of the former including some typical examples. First let us turn to his definition of overt category:

An overt category is a category having a formal mark which is present (with only infrequent exceptions) in every sentence containing a member of the category. The mark need not be part of the same word to which the category may be said to be attached in a paradigmatic sense; i.e. it need not be a suffix, prefix, vowel change or other "inflection," but may be a detached word or a certain patterning of the whole sentence. (Carroll,1956, p. 88)

Taking into account Whorf's definition of overt category, I think an overt category is found with apparent markers in all or nearly all sentences. According to Whorf, if a subject is required in a sentence with its plural form, the paradigmatic principle works. The nouns serving as the subject are not restricted to the selection of those with affixed, for example, 's', vowel change or other inflectional changes, but some individual words, sometimes together with other words, which form a fixed "patterning", also have this sort of function.

In English, for instance, the plural of noun is an overt category because it is either marked by the suffix 's' or a vowel change, or by other features of the phrase or sentence they occur with, e.g. the form of the verbs, the manner of use of the articles. In the plural form, there exists no inflectional ending in the noun fish, but its number may be represented in the shape of the verb (the fish are going to be transported to the big cities) or in the absence or presence of the definite article (fish died, the fish appeared). The overt category can be illustrated with more plural examples. In the sentence "the Japanese left", the definite article together with lack of a singular marker like Chinese, Indian, represents the plural form. "The potential mode of the verb" is another overt category because it is marked by the morpheme 'can' or 'could'.

After an elusive statement of overt categories, Whorf turned to his famous explanation of covert categories. In his essay, he wrote:

A covert category is marked, whether morphemically or by sentence pattern, only in certain types of sentences and not in every sentence in which a word or element belonging to the category occurs. The class-membership of the word is not apparent until there is a question of using it or referring to it in one of these special types of sentence, and then we find that this word belongs to a class requiring some sort of distinctive treatment, which may even be the negative treatment of excluding that type of sentence. This distinctive treatment we may call the REACTANCE of the category. (Carroll, 1956, p. 89)

According to Whorf's original intention, covert category is of greater importance in understanding people's thoughts, thus it deserves more words here. Notice that in this passage, Whorf stressed that covert category is marked in the language. Its marking, however, appears in some certain contexts. In my analyses, Whorf's markers of covert category include features of position, order in the sentence and negative characteristics. As (Foley, 2001, p.200) summarized, covert categories are those without an ever present formal marker, but are indicated by their possibilities of combination with other words in various constructions. Some examples are given to illustrate this.

Intransitive verbs in English are covert category because they do not have a particular suffix or marker that distinguishes them from other types of verbs. For intransitive verbs, some rules cannot apply. Only when some kinds of rules are applied, such as passive voice, causative voice do we realize that some English verbs like go, lie, sit, gleam, sleep, arrive, appear, rejoice share the same characteristic of usage and differ from other verbs, e.g. cook, push, see, give, etc. For example, we cannot use the intransitive verbs in passive sentences. We cannot say it is being arrived or it was gone. Another type of covert category which is analyzed by Whorf is English gender. Personal given names, for example, fall into this category. Foreign languages learners have to learn them before the command of their usage. Specifically, they have to know in advance that "Lily" belongs to "she" group and "Tom" to the "he" group. Whorf concluded that "[t]he mistakes in English gender made by learners of that language, including those whose own languages are without gender, would alone show that we have here covert grammatical categories" (Carroll, 1956, pp. 90-91). In his essay, Whorf also included English adjective in covert category. We also find an interesting fact that Whorf sometimes used an alternative set of terms to refer to overt category and covert category, phenotype and cryptotype respectively. He initially used the term cryptotype in order to emphasize the characteristics and its application:

A covert linguistic class may not deal with any grand dichotomy of objects, it may have a very subtle meaning, it may have no overt mark other than certain distinctive "reactances" with certain overtly marked forms. It is then what I call a CRYPTOTYPE. (Carroll, 1956, p. 70)

From the statement above, it may be easily concluded that, the term involves two senses, one with obscure meaning and the other with an absence or a lack of overt marking. As for phenotype, Whorf at first meant to use it to refer to the conjunction of clear meaning and regular marking: 
I give the name PHENOTYPE to the linguistic category with a clearly apparent class meaning and a formal mark or morpheme which accompanies it; i.e., the phenotype is the "classical" morphological category. (Carroll, 1956, p. 72)

In view of the roles and functions in a language, Whorf also noticed that overt categories cannot be independent of covert categories (Carroll, 1956, p. 105). Each plays a part in providing a full understanding of the category of a language (The Hopi is such a typical language):

The meaning of a PHENOTYPE, though ostensibly plain, can really not be completely understood in all its subtlety until the cryptotypes that go with it have been dredged up from their submerged state and their effective meanings to some extent brought into consciousness. Thereupon, the different effects produced by the same phenotype with different crypotypes, and vice versa, result in a more pronounced consciousness and clearer understanding of the phenotype itself. (Carroll 1956, p.109)

Commonly speaking, the meaning of phenotype is understood more easily. Nevertheless, phenotypes alone cannot express the meaning entirely without the help of crypotypes. It is when the crypotypes which accompanies the phenotypes are brought effectively into consciousness that the meaning of phenotypes can be clearly comprehended.

Further, Whorf observed that ideas were not merely a pile of words, and a language that was simple with overt forms might be actually complicated in its covert categories:

It may turn out that the simpler a language becomes overtly, the more it becomes dependent upon crypotypes and other covert formations, the more it conceals unconscious presuppositions, and the more its lexations become variable and indefinable. (Carroll, 1956, p. 83)

In my opinion, Whorf's statement actually indicates that any simple treatment of a language may fail to understand its underlying meanings. The seemingly overt structures in a language are represented by the crypotypes, after his illuminating study of the Hopi language, Whorf found that the Hopi language is analyzed by the concept of cryptotype. Nevertheless, it could not be applicable to all languages (Carroll, 1956, p. 110).

\subsection{The Significance of the Recognition of Covert Categories}

The recognition of covert categories or cryptotypes is of great significance in anthropological linguistics for a couple of reasons. Initially, the belief in cryptotypes means that languages that may seem rather 'simple' at the lexicon level might in fact be more complicated at a more covert level (Carroll,1956, p. 83). He argued that investigating covert category might be particularly helpful in uncovering the true nature of linguistic thinking. Thus, linguists are not only paying attention to the research on the SAE, but on some minority languages used in some remote throughout the world. For my part, Whorf's achievement in covert categories actually paved a way for the subsequent researches.

And then, it demonstrates that the differences of languages never lie in the aspect of what the individual words resemble or can do, but lie in the aspect of what they do not or cannot do. This notion was subsequently developed by a wellknown figure - Chomsky who innovatively put forward the notion of "deep structure"(see more in the monograph of Chomsky "The Minimalist Program) . Most importantly, by careful analyses of overt and covert categories, especially the latter, Whorf made an effort to reduce the "superiority of standard average European languages", aiming to achieve the goal of "brotherhood of thought" (Carroll, 1956, p. 27).

\subsection{Whorf's Studies on Hopi and Mayan Languages}

Some of Whorf's writings are related to his research on the Hopi and Mayan languages and cultures. This section is keeping an eye on three essays written in the mid-1930s and the 1940s in Carroll's collection of Whorf's work: "An American Indian Model of the Universe", "A Linguistic Consideration of Thinking in Primitive Communities" and "Decipherment of the Linguistic Portion of the Maya Hieroglyphs".

As we all know, Whorf's most famous contribution to linguistic theory is his emphasis on the relationship between language and worldview. As Liu (2002, p. 158) describes about Whorf's linguistic relativity, we see the world in the way that our language describes it, so that the world we live in is a linguistic construct. Whorf believed that the Hopi language and culture contains a theory of the structure of the universe which he often called "metaphysics". In Whorf's illuminating study of the Hopi, such a structure is particularly evident when it is carefully examined by someone whose native language is entirely different from it. "Thus, the Hopi language and culture conceals a METAPHYSICS, such as our so-called naïve view of space and time does, or as the relativity theory does; yet it is different metaphysics from either"(Carroll, 1956, p. 58). For Whorf, the aim of linguistic analysis is to depict such a worldview. In his paper "An American Indian Model of the Universe", it is not difficult to see that Whorf made a detailed statement about the Hopi's time and space compared with the English structures and system. He affirmed that "after long and careful study and analysis, the Hopi language is seen to contain no words, grammatical forms, constructions or expressions that refer directly to what we call 'time' or to past, present, or future..."(Carroll, 1956, p. 57). Therefore, "In this Hopi view, time disappears and space is altered, so that it is no longer the homogenous and instantaneous timeless space of our supposed intuition or of classical Newtonian mechanics"(Carroll, 1956, p. 58). In refuting the traditional view that the Hopi is flawed metaphysics, Whorf summarized that their cultural assumptions or ideas as reflected in their own language illustrated an awareness of time and space which are totally different from that of speakers of English. In other words, there existed different ways of knowing the Hopi and the English speakers.

Because Whorf argued that consciousness was determined culturally, and not genetically, he claimed that one could have an understanding of the consciousness of the speakers of a language by a systematic study of their language. Still 
take metaphysics for example, in Whorf's opinion, "the metaphysics underlying our own language[English], thinking, and modern culture (I speak not of the recent and quite different relativity metaphysics of modern science) imposes upon the universe two grand COSMIC FORMS, space and time..."(Carroll, 1956, p. 59). In Hopi, on the other hand, Whorf accounted for the phenomenon that there were also two grand cosmic forms: objective and subjective. From Whorf's explanation, objective was "all that is or has been accessible to the senses, the historical physical universe, in fact, with no attempt to distinguish between present and past, but including everything that we call future"(Carroll, 1956, p. 59). The subjective, Whorf maintained, contained "everything that appears or exists in the mind" or the own expression of the Hopi "HEART". From the above statements, it may be deduced without difficulty that people with different languages have got different ways of looking at the world.

Included in the anthology by Carroll, the essay "Decipherment of the Linguistic Portion of the Maya Hieroglyphs" shows Whorf's interest in the American Indian language, the Mayan language. The essay, which was read before the Section on Anthropological Sciences of the English American Scientific Congress, was aimed at deciphering a brief extract from one of three Maya codices. As Whorf argued, the Maya writing system was represented by a group of signs and combination of signs denoting a particular subject matter(see more in the anthology by Carroll ,1956, pp. 17374). To be specific, those signs refer to numerals, period of time, and terms of the calendar. Whorf observed that mathematical relations were found between the signs and a system of mathematics was constituted by the use of those signs. Whorf, however, paid attention to the grammatical or linguistic relations instead of the mathematical one. Thus, Whorf's examples of decipherment in his essay were 23 symbols which were chosen from the several hundreds found in the whole Maya literature. Besides the reading of a few individual words, he led us to read a short sentence written in Maya hieroglyphs. Naturally, he put the sentence into English. In terms of his efforts made to decipher the individual symbols and translate the short sentence from Maya into English, Whorf summarized as follows:

The importance of this decipherment and translation is quite independent of the interest or lack of interest of the subject matter. As far as concerns the information which this translation gives us about the Maya, or about its own subject matter, it is quite trivial; it is no more than we could have gathered from the pictures alone. Its importance is linguistic and philological-linguistic because it gives information about the structure of a language, as far as the writing can express it, at a certain period of past time; philological because it is precedent to the study of a literature and of culture as reflected in this literature, at a period of past time and in a historical context and perspective. (Carroll, 1956, p. 195)

Whorf did believe that once the scholars overcame the linguistic difficulties in the process of decipherment and translation, the study actually became more and more philological. If so, the individual Maya hieroglyphs and grammar would surely play a dominant role not only in reading but also in comprehending "the allusions, the references, the nonlinguistic contexts, the cultural patterns" which he called philology. But Whorf, at the same time, emphasized that linguistics was prior to philology. "Only in this way can we ever hope to understand the history and culture of the Maya" (Carroll, 1956, p. 198).

Whorf's definition of covert categories plays an important role in helping people understand the deeper meaning of such a language as Hopi. In his statement, it is because the interaction of the overt categories and covert categories that people understand the language better. The covert categories are more important that overt categories if people want to explore the internalized meaning of a language.

\section{Whorf and contrastive linguistics}

The previous researches seldom concentrate on Whorf's notion towards contrastive linguistics. Actually, contrastive method is a major way for Whorf to investigate the different languages and, because of the use of this, his goal of contrasting English and Hopi is achieved. Although Whorf is not the first to give an exact definition of contrastive linguistics in the academic circle, his devotions to contrastive linguistics are never ignored.

\subsection{Whorf's Definition of Contrastive Linguistics}

Whorf did not express too much on the subject of contrastive linguistics in his essays. Only when reading his paper "Language and Logic", do we find that Whorf distinguished "comparative linguistics" and "contrastive linguistics". He wrote:

Botanists and zoologists, in order to understand the world of living species, found it necessary to describe the species in every part of the globe and to add a time perspective by including the fossils. Then they found it necessary to compare and contrast the species, to work out families and classes, evolutionary descent, morphology, and taxonomy. In linguistic science a similar attempt is under way. The far-off event toward which this attempt moves is a new technology of language and thought. Much progress has been made in classifying the languages of earth into genetic families, each having descent from a single precursor, and in tracing such developments through time. The result is called "comparative linguistics." Of even greater importance for the future technology of thought is what might be called "contrastive linguistics." This plots the outstanding differences among tongues - in grammar, logic, and general analysis of experience. (Carroll f, 1956, p. 240)

Obviously, contrastive linguistics is derived from comparative linguistics. As a matter of fact, it is because of this great distinction between "comparison" and "contrast" that "contrastive linguistics" finally formed and developed. As far as Whorf is concerned, researchers have made great advances in the classification of the languages across the world. Great attention has been drawn to the origin and the diachronic developments of each language. The researchers aim to find the changes of a language from its past to the present time or perhaps during a certain period of time. However, 
great importance is attached to the term "contrastive linguistics" which investigates the huge differences among languages in grammatical structures, logic and experience. My understanding is that the shift from comparative linguistics to contrastive linguistics means a revolutionary step, which may help linguists find more similarities and differences across languages so as to establish a link among them.

\subsection{Whorf's Contributions to Contrastive Linguistics}

Whorf naturally arrived at several conclusions based on his linguistic relativity. Firstly, in order to have an understanding of human's wisdom, it is of necessity to study and contrast a variety of languages, especially those which are extremely distinctive in nature because diversity exists in languages and human's thinking modes. In his paper, "science and linguistics," Whorf claimed:

If a rule has absolutely no exceptions, it is not recognized as a rule or as anything else; it is then part of the background of experience of which we tend to remain unconscious. Never having experienced anything in contrast to it, we cannot isolate it and formulate it as a rule until we so enlarge our experience and expand our base of reference that we encounter an interruption of its regularity. (Carroll, 1956, p. 209)

Again he added:

When linguistics became able to examine critically and scientifically a large number of languages of widely different patterns, their base of reference was expanded; they experienced an interruption of phenomena hitherto held universal, and a whole new order of significances came into their ken. (Carroll, 1956, p. 212)

Secondly, Whorf was then worried about the contrastive linguistics which focused on the Indo-European languages on which the formation of one tongue was based.

The rather startling conclusion is not so apparent if we compare only our modern European languages, with perhaps Latin and Greek thrown in for good measure. Among these tongues, there is unanimity of major pattern which at first seems to bear out natural logic. But this unanimity exists only because these tongues are all IndoEuropean dialects cut to the same basic plan, being historically transmitted from what was long ago one speech community; because the modern dialects have long shared in building up a common culture; and because much of this culture, on the more intellectual side, is derived from the linguistic backgrounds of Latin and Greek. Thus this group of language satisfies the special case of the clause beginning "unless" in the statement of the linguistic relativity principle at the end of the preceding paragraph. (Carroll, 1956, p. 240)

This passage implies that modern European languages belong to the same family and they all date back to one speech community. As time went by, they formed a common culture. Whatever aspects the researchers study those languages, one fact they cannot neglect is that all those languages they focus on are derived from Latin and Greek. If they do so, they may be confused by the research direction of the contrastive linguistics.

Whorf even mentioned that when "modern Chinese or Turkish scientists describe the world in the same terms as Western scientists" do, they have not corroborated from their native posts of observation. Rather, "they have taken over bodily the entire Western system of rationalizations". Thus, he severely criticized the idea that in the future the world would be governed in one language. He further stated:

For this reason I believe that those who envision a future world speaking only one tongue, whether English, German, Russian, or any other, hold a misguided ideal and would do the evolution of human mind the greatest disservice. Western culture has made, through language, a provisional analysis of reality and, without correctives, hold resolutely to that analysis as final. The only correctives lie in all those other tongues which by acons of independent evolution have arrived at different, but equally logical, provisional analyses. (Carroll 1956, p. 244)

Thirdly, Whorf concluded that in conducting contrastive research and analysis among languages, those languages which are structurally different from our mother tongue, English, had to be selected. He wrote:

But the difficulty of appraising such a far-reaching influence is great because of its background character, because of the difficulty of standing aside from our own language, which is a habit and a cultural non est disputandum, and scrutinizing it objectively. And if we take a very dissimilar language, this language becomes a part of nature, and we even do to it what we have done to nature. We tend to think in our own language in order to examine the exotic language. Or we find the task of unraveling the purely morphological intricacies so gigantic that it seems to absorb all else. Yet the problem, though difficult, is feasible; and the best approach is through an exotic language, for in its study we are at long last pushed wily-nilly out of our ruts. Then we find that the exotic language is a mirror held up to our own. (Carroll, 1956, pp. 137-138)

With these statements, the writer is going to lead the readers to look at Whorf's most thoroughgoing examples. By reading his essays, it is known to us that Whorf approached the empirical studies of his view that language may influence thought into two ways: firstly, the typical Boasian method of contrastive analysis of individual examples in particular languages; and secondly, a comprehensive and detailed comparison of a set of linguistic systems in two languages, with the aim of reaching such conclusions that the differences in languages may lead to different modes of habitual thinking, the conceptualization of experience, of their speakers. In order to provide an illustration of his first research method, he contrasted Shawnee, an Algonkian language of eastern North America, and English. Shawnee has two verbs, both of which based on the same root. If they are translated into English, the two meanings of the two words are different. It seems that the two English sentences have nothing in common in that they are expressed in two 
different verbs. According to Whorf, it was because of these differences in the selection of verbs that English speakers are unlikely to conceptualize these expressions as having much in common. Nevertheless, in Shawnee, the same verb root is used, making its speakers to conceptualize the expressions as quite similar.

Based on the above study, I think that translation must be a thorny problem for communication. House(2000, p.73) once suggested that if languages display such striking grammatical differences , and if-as Whorf maintains-linguistic form has a truly "tyrannical hold" upon our way of thinking and perceiving, one might conclude that the theoretical possibility of translating, either from and into SAE and American Indian languages, or from and into many other languages, seems to be denied.

According to Whorf, the grammatical differences will actually predispose speakers of Shawnee and English to conceptualize them in different terms, Shawnee as alike, English as unlike: "facts are unlike to speakers whose language background provides for unlike formation of them" (Carroll, 1956, p. 235).

In his essay, "The Relation of Habitual Thought and Behaviour to Language" (Carroll, 1956, pp. 134-59), a global comparison of linguistic systems in two languages, the Hopi and English, and habitual ways of thinking shown in cultural practice is found. In his essay, Whorf contrasted the linguistic patterns and habitual thought or experience of Hopi with what those of he calls Standard Average European (SAE), holding the view that few differences were found among English and other European languages in terms of the characteristics that he is studying. Whorf contrasted English and Hopi with respect to the grammatical category of number, pointing out that the plural category in English applies to both perceptually tangible objects, like men and imaginary groupings, such as cycles, like days, which are never perceptually tangible. Whorf's elaboration of this can be found next:

In our language, that is SAE, plurality and cardinal numbers are applied in two ways: to real plurals and imaginary plurals. Or more exactly if less tersely: perceptible spatial aggregates and metaphorical aggregates. We say 'ten men' and also 'ten days.' Ten men either are or could be objectively perceived as ten, ten in one group perception - ten men on a street corner, for instance. But 'ten days' cannot be objectively experienced. We experience only one day, today; the other nine (or even all ten) are something conjured up from memory or imagination. If 'ten days' be regarded as a group it must be as an "imaginary," mentally constructed group. Whence comes form this mental pattern? Just as in the caste of the fire-causing errors, from the fact that our language confuses the two different situations, has but one pattern for both. When we speak of 'ten steps forward, ten strokes on a bell,' we are doing the same thing as with 'days.' CYCLICITY brings the response of imaginary plurals. But a likeness of cyclicity to aggregates is not unmistakably given by experience prior to language, or it would be found in all languages, and it is not. (Carroll, 1956, p. 139)

Whorf's description presents Hopi as being fundamentally different. The grammatical categories of plurals and cardinals are only used with nouns referring to object-like entities while ordinals are used to count the tensors: "first day," "second day," "third day," and the like. Whorf presented a summary of this thus:

In Hopi there is a different linguistic situation. Plurals and cardinals are used only for entities that form or can form an objective group. There are no imaginary plurals, but instead ordinals used with singulars. (Carroll, 1956, p. 140)

According to Whorf, when the Hopi speakers count, they are not counting the actual number of objects, but counting successive reappearance of the same thing. Whorf explained this as such:

Time is mainly reckoned "by day"(talk,-tala)or "by night" (tok), which words not nouns but tensors, the first formed on a root "light, day," the second on a root "sleep." The count is by ORDINALS. This is not the pattern of counting a number of different men or things, even though they appear successively, for, even then, they COULD gather into an assemblage. It is the pattern of counting successive reappearances of the SAME man or thing, incapable of forming an assemblage. The analogy is not to behave about day-cyclicity as to several men ("several days"), which is what WE tend to do, but to behave as to the successive visits of the SAME MAN. (Carroll, 1956, p. 148)

Whorf provided some evidence to believe that English speakers conceive of units of temporal intervals as countable tangible objects. He noticed that the "fashion of speaking" that English speakers use to talk about time clearly exhibited this conceptualization (Whorf, 1956, pp.152-156): we spend /save/lose/buy time; time is money; I never have enough time. Besides, Whorf claimed that our very conception of history is due to our conception of objectivized time:

But OUR objectified time puts before imagination something like a ribbon or scroll marked off into equal spaces, suggesting that each can be filled with an entry. Writing has no doubt help toward our linguistic treatment of time, even as the linguistic treatment has guided the uses of writing. Through this give-and-take between language and the whole culture we get, for instance:

1. Records, diaries, bookkeeping, accounting, mathematics stimulated by accounting.

2. Interest in exact sequence, dating, calendars, chronology, clocks, time wages, time graphs, time as used in physics.

3. Annals, histories, the historical attitude, interest in the past, archaeology, attitudes of introjection toward past periods, e.g. classicism, romanticism. (Carroll, 1956, p. 153)

Hopi culture shows a different conceptualization according to Whorf. It is known that their view of time intervals is of 
cycles repeating the same man or thing. Hence, each day is not in nature different from the last. That is why Hopi society does not understand the English proverb "tomorrow is another day". In their understanding, the return of the day is the same as the return of the same person. Unlike the English speakers who pay attention to change, they lay emphasis on the continuity and persistence.

After his intensive and detailed comparative study of English and Hopi linguistic and cultural patterns and their habitual thinking, Whorf is led to draw the following conclusion:

Concepts of "time" and "matter" are not given in substantially the same form by experience to all men but depend upon the nature of the language or languages through the use of which they have been developed. They do not depend so much upon ANY ONE SYSTEM (e.g. tense, or nouns) within the grammar as upon the ways of analyzing and reporting experience which have become fixed in the language as integrated "fashion of speaking" and which cut across the typical grammatical classifications, so that such a "fashion" may include lexical, morphological, syntactic, and otherwise systematically diverse means coordinated in a certain frame of consistency. (Carroll, 1956, p. 158)

From what we have read in Whorf's original works, we may easily find that those ideas mentioned above constitute the fundamental contents of Whorf's notion towards contrastive linguistics. The writer here cites Pan Wenguo and Tan Huimin(2005) as saying that contrastive research, to a large extent, strays too far from Whorf's initial ideas mainly because the researchers opted the languages similar to their own language as objectives consequently little differences were found among the languages. Recently the writer read monograph concerning Chinese linguistics in which the author makes an effort to differentiate Chinese from English . in his choices of research objects, we see that those languages are different in nature and do not belong to the same familiy(see more in Shen Xiaolong's monograph).

In summary, Whorf maintained that linguists had studied the Indo-European languages for such a long time that they might use the generalized "formulas" to handle relations with other languages which have a "superficial similarity" with Indo-European languages but actually differ greatly from them. Thus contrastive analysis of different languages in nature is the core of Whorf's study and contrastive study of languages is his methodology throughout his research activities.

\section{Whorf and psycholinguistics}

Sapir (1921)had asserted that languages are diverse in the way that they structure reality, but he did not fully developed this thesis that these linguistic differences may have influence upon certain modes of thought(Carroll, 2008, p.396). As far as the studies on Whorf are concerned, some of them are focusing on his ideas from the psychological aspect. Whorf himself once said that he was the first man to recognize the submerged layer of meaning. Thus, since his time, quite a few psycholinguists have concerned with the more deeply convolved aspects of grammatical structures. Whorf's insight into psycholinguistics can be seen in his essay "A Linguistic Consideration of Thinking in Primitive Communities" in which he explored mainly the interrelationships among language, culture and cognition.

In this essay, Whorf first criticized the research limitations of ethnologists, who studied a primitive community, arguing that what they emphasized was not the psychological aspects but seemingly easier matters when it comes to the questions: "What do these people think? How do they think? Are their intellectual and rational process akin to ours or radically different?" (Carroll, 1956, p. 65). Meanwhile, Whorf added that the study of a native community from psychology alone was not enough and the problem of thought and thinking was fundamentally cultural. To be more specific, Whorf regarded thought and thinking as a "cohesive aggregate of cultural phenomena" which was defined as a language.

With this point, we find that Whorf would like to investigate thinking through linguistics. In Whorf's opinion, the research was best approached through the joint efforts of linguists such as Franz Boas, Leonard Bloomfield and Edward Sapir. Whorf also focused his attention on the work of the psychologists, one of whom was Carl Jung who distinguished four basic psychic functions. According to Jung, two psychic functions were rational: thinking and feeling; and two were irrational: sensation and tuition. Whorf further explained those four functions and categorized them from either linguistic or nonlinguistic perspectives. He affirmed that "it is evident to a linguist that thinking defined by Jung, contains a large linguistic element of strictly patterned nature, while feeling is mainly nonlinguistic, though it may be a vehicle of language" (Carroll, 1956, p. 66). After his conclusion that sensation and intuition were nonlinguistic and that feeling was mostly non-linguistic, he maintained that language played a pivotal role in the process of thinking and it was the means to understand the psychic function of thinking, "we are thus able to distinguish thinking as the function which is to a large extent linguistic" (Carroll, 1956, p. 66).

Whorf then made a mention of SILENT thinking (thinking without speaking). He claimed that silent thinking was seldom discussed deeply. Traditionally, people thought silent thinking was no more than suppressed talking or some mumble words, a view which is similar to the linguistically simple "common sense". The latter does not realize that talking itself means using a culturally complicated structure system. As is known to all, sense or meaning is not actually a pile of words or morphemes, but they are from the "patterned relations" between words or morphemes (Carroll, 1956, p. 67). According to Whorf, words and morphemes were only motor reactions. Once they were used to make up the categories and patterns on which linguistic meanings dwelled, the words and morphemes were not motor reactions, a process which the individuals did not observe. After the elaborate analyses of the relations between words or morphemes and thought, Whorf drew such a conclusion that:

It is not words mumbled, but RAPPORT between words, which enables them to work together at all to any 
semantic result. It is this rapport that constitutes the real essence of thought insofar as it is linguistic, and that in the last resort renders the mumbling, laryngeal quiverings, etc., semantically de trop. (Carroll, 1956, p. 67)

Subsequently, Whorf pointed out that the real analysis of language relied on scientific grammar, not on motor quiverings corresponding to suppressed words and morphemes, or on actual words and morphemes. An example concerning gender in English is given. "He" and "she" are only motor reactions of the English gender pronouns. The gender nouns, such as boy, girl, uncle, aunt, grandfather, grandmother, husband, wife, including tens of thousands of given names like Tim, Tom, Jack, Lucy, Lily, Diana cannot be seen obviously by their forms, that is, they have no apparent grammatical mark of gender. But the speakers of the English language can readily divided them into the proper "he" or "she" group. Of course they need not do so intentionally but on these occasions where a special discourse really needs the speakers' clear classification. Why is it so? Whorf argued that it was because of this linkage-bond that each of the thousands of gender nouns was connected exactly with the word "he" or the word "she." Whorf explored it from the psychological stand, concluding that:

These thousands of linkage processes rallying around the common point of the pronoun and ramifying to all the thousands of nouns of one gender form a sort of psychic complex belonging to (1) the nonmotor and nonactualized realm, (2) the thinking function in Jung's definition, (3) the linguistic and cultural order.

(Carroll, 1956, p. 68)

Whorf did not go further to give a full account of the mechanisms of such a complex. He just affirmed that habitual consciousness was a dominant factor in classifying two sex classes.

And then, his descriptions of overt and covert categories, which are discussed at large in the previous section, have been appreciated by a number of psychologists and linguists, one of whom is Penny Lee whose comments on Whorf's “cryptotype, psycholinguistic patterning”(Carroll , 1956, p. 74) are:

No one to my knowledge, however, has commented on the possibility that had Whorf lived to clarify and elaborate his ideas on 'psycholinguistic patterning', psycholinguistics might have developed with very different characteristics to the discipline which did eventually emerge under that name. (Lee, 1996, p. 160)

Whorf stressed that "Awareness of psychological undercurrents is the last thing to arrive in the conquest of linguistic understanding, both in the individual and in history" (Carroll, 1956, p. 73). To document this assertion, Whorf sketched a history of linguistics stressing that the idea of "psycholinguistic patterning and language as part and parcel of a culture" (Carroll, 1956, p. 74) was ignored until d'Olivet. According to Whorf, from the ancients to d'Olivet, linguistics could be characterized as mere dealing with "formal and overt structures" (Carroll, 1956, p. 74). He also credited d'Olivet with reorganizing "the treatment of verb conjugations on a psycholinguistic basis" Carroll (1956, p. 75). Whorf acknowledged the scholarship of a James Byrne (1820-1897), an Irish scholar "who independently found, or thought he found, a correlation between language structures and two types of mentality, one quick-reacting, quickthinking, and volatile, the other slow reacting, slow-thinking, but more profound and phlegmatic" (Carroll, 1956, p. 77). However, Whorf concluded that Byrne could not "have a sui generis configurative report on language as d'Olivet had done" (Carroll, 1956, p. 77). Whorf claimed that Boas in his handbook of American Indian languages (1911) "showed for the second time in history, but for the first time in a scientific manner, how a language could be analyzed sui generis and without forcing the categories of 'classical' tradition upon it" (Carroll, 1956, p. 78).

In the third part of this essay, Whorf maintained that the linguistic survey of thinking in the primitive communities was significant for anthropology in two respects. First, the investigators with both ethnological and psychological-linguistic backgrounds were encouraged to carry out such a survey in order to achieve a fertilizing effect on one another. Such a combination of the two may lead to a successful analysis of the discovery made by ethnologists that the Hopi speak about clouds in their rain prayers, etc., as if clouds were alive into a grammar which can explore the deeper meaning of the linguistic form. With this, Whorf was led to the following conclusion:

Language thus should be able to analyze some, if probably not all, of the differences, real or assumed, between the mentality of so-called primitive peoples and modern civilized man. (Carroll, 1956, pp. 79-81)

These are all questions, essentially anthropological, to which a liaison between ethnology and psychological linguistics would seem to offer the soundest approach.

Second, the reason why linguistic consideration of thinking in primitive communities is of significance for anthropology is that it is closely related with the future development of the human being. Whorf embraced the view that "the future developments of thinking are of primary importance to the human species" (Carroll ,1956, p. 83). There are possibilities that are open to thinking and that are inevitably bound up with systems of linguistic expression. It is with those possibilities that people recognize relationships at the mental or intellectual level. As time goes by, the relationships will become much wider, more significant.

Obviously, Whorf argued that it was of necessity to exercise the linguistic consideration of thinking because the knowledge that the survey unlocked was not confined to the academic circles and it might exert great influence on the history. We may find that Whorf's linguistic research has gone beyond language itself. Superficially, he explored some individual examples of Hopi, but actually, he aimed to find out the internalized meaning of the linguistic forms, which exactly manifests his philosophy of language. 


\section{Conclusion}

Although nearly a century passed after the year Benjamin Lee Whorf was born, his theory complex is of great interest to linguists and researchers. Whorf's arguments have evoked a great many heated discussions and disputes in the academic circle. However, according to Lee $(1996,2000)$, the linguistic relativity is just part of Whorf's abundant ideas. Apart from the relativity principle, Whorf's ideas are interpreted in many domains. Specifically, Whorf actually explored the relationship between language and thought in such interdisciplinary fields as anthropological linguistics, contrastive linguistics and psycholinguistics. With these, Whorf's ideas are presented in some different perspectives. Although Whorf died young and did not leave as many paper as we had expected, he propelled us to set foot upon a number of domains with relation to linguistics. It is with his great contribution that we are able to begin to explore deeper in those fields.

\section{References}

Carroll, D. W. (2008). Psychology of language. Beijing: Foreign Language Teaching and Research Press.

Carroll, J. B. (Ed.). (1956). Language, Thought, and Reality: Selected writings of Benjamin Lee Whorf. Cambridge, MA: MIT press.

Chomsky, N.(2012). The Minimalist Program. Beijing: Foreign Language Teaching and Research Press; The MIT Press.

Foley, W. A. (2001). Anthropological linguistics: An introduction. Beijing: Foreign Language Teaching and Research Press.

House, J. (2000). Linguistic relativity and translation. In M. Putz \& M. H. Verspoor (Eds.), Explorations in linguistic relativity (PP. 69-88). Amsterdam: John Benjamins.

Lee, P. (1996). The Whorf theory complex. Amsterdam and Philedelaphia: John Benjamins.

Lee, P. (2000). When is 'linguistic relativity' Whorf's linguistic relativity? In M. Putz \& M. H. Verspoor (Eds.), Explorations in linguistic relativity (PP. 45-68). Amsterdam: John Benjamins.

Liu, R. Q. \& Feng, Z. X. (2002). The theories and schools of linguistics. Nanjing: Nanjing Normal University Press.

Sapir, E. (1921). Language: An introduction to the study of speech. New York: Harcourt, Brace

Sapir, E. (1964). Conceptual categories in primitive languages. In Hymes, D.(ed), p.128

Wardhaugh, R. (2000). An introduction to sociolinguistics. Beijing: Foreign Language Teaching and Research Press.

Pan, W. G \& Tan, H. M. (潘文国, 谭慧敏), 2005, 《对比语言学: 历史与哲学思考》, 上海: 上海教育出版 社。

Shen, X.L. (申小龙), 2008, 《汉语与中国文化》,上海: 复旦大学出版社.

Yao, X.P. (姚小平) , 2002, 人类语言家沃尔夫的遗产一读《论语言、思维和现实》, 《外语教学与研究》(1): $75-77$. 